\title{
Biocidal potential of biosynthesized silver nanoparticles against fungal threats
}

\author{
M. Jannathul Firdhouse $\cdot$ P. Lalitha
}

Received: 2 July 2014/ Accepted: 7 September 2014/Published online: 18 September 2014

(C) The Author(s) 2014. This article is published with open access at Springerlink.com

\begin{abstract}
Microbes are the major cause for the hospitalacquired infections which lead to prolonged illness, disability or even death. The increasing microbial resistance calls for the search for newer drugs. Evolving nanotechnology in drug delivery produces drug action in lesser amounts and with several times more potency. In the present work, we have synthesized AgNPs using the aqueous extracts of Amaranthus dubius, Amaranthus polygonoides, Alternanthera sessilis, Portulaca oleracea, Pisonia grandis, and Kedrostis foetidissima. Sonication method yielded a facile and rapid method of biogenic synthesis of nanosilver. The TEM images revealed the synthesized AgNPs to be of size ranging between 6 and $23 \mathrm{~nm}$ without agglomeration. Antifungal activity of the synthesized AgNPs against $C$. albicans and S. cerevisiae carried out by agar well diffusion method showed good zones of inhibition disclosing the antifungal potential of the biogenic silver nanoparticles.
\end{abstract}

Keywords Silver nanoparticles $\cdot$ C. albicans .

$S$. cerevisiae $\cdot$ Antifungal activity

\section{Introduction}

The range and burden of infectious diseases have decreased the socioeconomic progress of India. Infectious diseases caused by faecally transmitted pathogens (enteric fevers, cholera, hepatitis $\mathrm{A}$ and $\mathrm{E}$ viruses) and zoonoses (rabies,

M. Jannathul Firdhouse · P. Lalitha $(\square)$

Department of Chemistry, Avinashilingam Institute for Home

Science and Higher Education for Women University,

Coimbatore 641043, Tamil Nadu, India

e-mail: goldenlalitha@gmail.com leptospirosis, anthrax) are not in the process of being systematically controlled. Microorganisms which bind to the host cell targets promoting host responses cause these diseases [1, 2].

Candida albicans causing candidiasis can be classified as superficial (vaginal thrush, oral and chronic mucocutaneous) and deep-seated (Candida myocarditis and Candida septicemia) and is one of the major clinical problems in India [3]. In United States, C. albicans is the causative of the fourth most hospital-acquired infection and US \$1 billion has been spent for the treatment annually. Progress of an infection leads to growth of fungal masses in the brain, heart and kidney contaminating indwelling catheters and finally enters the blood stream causing candidaemia. The dimorphic transition from yeast to mycelia form leads to the pathogenicity $[4,5]$.

A different but important problem is C. albicans infection in facial prostheses, which is made of silicone. This prostheses coated with AgNPs preserved the fibroblast cells from fungal infection compared to that of uncoated silicone prosthesis. The silicone coated with AgNPs $(50 \mathrm{mg} / \mathrm{L})$ is non-toxic to fibroblast cells, whereas silver nitrate coating produces a toxic effect. Therefore, silicone coated with AgNPs is biocompatible and it is the fitting method to prevent fungal infection in patients with maxillofacial prostheses [6].

Saccharomyces cerevisiae (Baker's yeast) is an organism preferable for the genetic research in this century. Preference of this single-celled eukaryotic species in research owes to its simple life cycle, short generation time, alternating haploid and diploid phases and easy-toidentify meiotic products. To gain deep understanding about organizing and regulating eukaryotic cells, microbiologists analyze genes by advanced technology. Genomic response to nanoparticles is used to assess toxicological 
impact at genetic levels using $S$. cerevisiae as a model eukaryote [7-10].

Silver, though toxic in nature, has good antimicrobial properties. Nanoparticles hold unique antimicrobial, optical and electrical properties and therefore find applications in various fields [11]. AgNPs own rich therapeutic properties. These motivate the researchers to extensively take up study on AgNPs. Therefore, the focus is on identifying silver nanoparticles as agents for fungal threats.

Production of silver nanoparticles is through various physical, chemical and biological methods [12]. Biogenic synthesis of AgNPs is more rewarding than conventional methods as it is freed from use of toxic solvents, high pressure and temperature. Preference is because of its ecofriendly nature, cost-effectiveness and ease of scalability for large-scale production [13, 14]. Plants are the major sources of therapeutic metabolites. There are reports on the synthesis of AgNPs using bacteria, fungi and plant extracts. But the advantage of quicker synthesis makes plant extracts an excellent choice for AgNPs synthesis. In the medical field, the most exploited nature of silver nanoparticles is the antimicrobial properties of AgNPs [15, 16]. Therefore, the present work aims at exploiting the medicinal value of these secondary metabolites in plants in the synthesis of AgNPs.

In our present work, preparation of AgNPs was through use of different plant extracts under sonication method. Considering the clinical problems, there is a need to provide a solution to the fungal threats. Therefore, it is aimed to explore the antifungal activity of AgNPs against $C$. albicans and $S$. cerevisiae by well diffusion method. The prepared AgNPs showed good zones of inhibition compared to that of the standard. The synthesized AgNPs presented minimum inhibitory effect against the tested fungi at a concentration of $200 \mu \mathrm{g}$.

\section{Materials and Methods}

\section{Materials}

Green leafy vegetables (Amaranthus dubius (AK), Amaranthus polygonoides (SK), Alternanthera sessilis (PGK), Portulaca oleracea (PAK), Pisonia grandis (PG) and Kedrostis foetidissima (KF)) were purchased from a retail shop in Coimbatore. Analytical grade silver nitrate was purchased from S D fine chemicals, India. Millipore water was used throughout the experiments.

Preparation of aqueous extract

The triply washed aerial portion $(20 \mathrm{~g})$ of the six plants (AK, SK, PGK, PAK, PG, and KF) cut into small pieces was boiled with $100 \mathrm{ml}$ doubly distilled water. The solutions were separately filtered through Whatman filter paper and refrigerated.

Synthesis of silver nanoparticles

Silver nitrate $(3 \mathrm{mM})$ and calculated volumes of plant extract were sonicated in a ultrasonic bath (Ultrasonics 1.5 L (H)). The formation of AgNPs indicated by reddish brown color was monitored by UV-visible spectroscopy. The formed nanosilver was centrifuged at 13,000 rpm for $15 \mathrm{~min}$ to remove the plant debris.

Characterization of synthesized silver nanoparticles

The synthesized AgNPs were analyzed by UV-visible spectroscopy using a Double beam spectrophotometer2202 (Systronics). XRD analysis was carried out for the nanosilver coated on a glass substrate by X'pert Pro X-ray diffractometer and the particle size was calculated using Debye-Scherrer's equation. The morphology of AgNPs was sighted by Scanning Electron Microscopy TESCAN with Vega TC software. The nanodimension of the synthesized AgNPs was established through recording TEM images using FEI's Tecnai ${ }^{\mathrm{TM}} \mathrm{G}^{2}$ Transmission Electron Microscope. The imaging of the sonicated AgNPs was enabled by depositing a few drops of suspension on a carbon film 200 mesh copper grid of $2.8 \mathrm{~mm}$ diameter and the solvent was evaporated prior to recording TEM.

Microorganisms used for the study

Antifungal activity was carried out for the biosynthesized AgNPs by agar well diffusion method against clinically isolated fungi Candida albicans and Saccharomyces cerevisiae.

Antifungal screening

The inoculums for the experiment were prepared in fresh Sabouraud's broth from preserved slant culture. Standardization of the inoculum to McFarland standards was by adjustment of culture turbidity by sterile saline addition. A sterile cotton swab was dipped in the inoculum and streaked over the entire surface of medium. The inoculums were then left to dry at room temperature with the lid in closed condition.

Fungal strains (Candida albicans and Saccharomyces cerevisiae) were inoculated into the broth under aseptic condition and incubated at $35^{\circ} \mathrm{C}$ for $18 \mathrm{~h}$. After the incubation period, the fungi were swabbed on the agar plate using a sterile cotton swab. Each fungus was swabbed separately and each plate was divided into six parts. Wells 
(6 mm) were made on Muller Hinton Agar plate using a sterile cork borer under aseptic condition. The AgNPs $(600 \mu \mathrm{g} / 20 \mu \mathrm{l})$ biosynthesized using 6 different plant extracts (AKG, SKG, PGKG, PAKG, PGG, and KFG) and Fluconazole (control) were loaded onto the marked wells using a micropipette and incubated at $37{ }^{\circ} \mathrm{C}$ for $24 \mathrm{~h}$. The zones of inhibition produced were recorded in millimeter.

Measurement of minimum inhibitory concentration (MIC)

Different concentrations of $\operatorname{AgNPs}(5,10,15,20,25 \mu \mathrm{l})$ were loaded onto the marked wells and incubated at $35{ }^{\circ} \mathrm{C}$ by the aforesaid method. The MIC of AgNPs embedded in plant extracts AKG, SKG, PAKG, PGKG, PGG, and KFG was ascertained from the zone of inhibition values obtained at different concentrations of each AgNP after $24 \mathrm{~h}$.

\section{Results and Discussion}

Addition of silver nitrate solution to the aqueous extracts of A. dubius, A. polygonoides, A. sessilis, P. oleracea, P. grandis, and $K$. foetidissima produced reddish brown color in 10-30 min (Fig. 1). The results suggest 1:10 ratio of plant extract and silver nitrate to produce nanosilver for AK, SK, PGK, and PAK plant extracts and 1:1 ratio for PG and KF plant extracts. The variation in time for the formation of AgNPs may be due to the difference in the composition of the secondary metabolites present in the plant extracts. These metabolites act as capping agents and aid in the reduction of $(\mathrm{Ag}+)$ to $(\mathrm{Ag} 0)$.

The aqueous extracts of blackberry, blueberry, pomegranate and turmeric at room temperature under vigorous stirring for overnight produce silver nanoparticles [17]. The color changed from green to brown for Murraya koenigii-assisted silver nanoparticles within 1 hour of

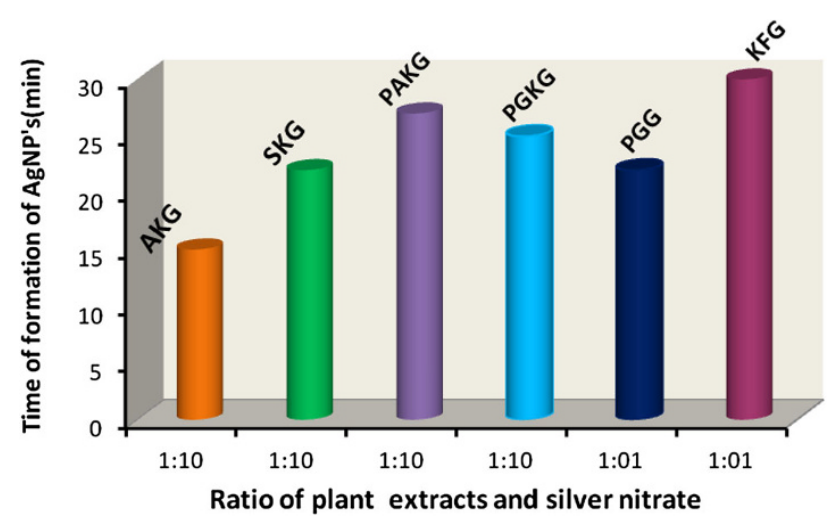

Fig. 1 Graph depicting time of formation of silver nanoparticles using the aqueous extracts of AK, SK, PAK, PGK, PG, and KF incubation in darkness under room temperature [18]. The variation in the time of formation of AgNPs owes to the phytoconstituents present in the plant extracts used for the synthesis.

UV-visible spectral analysis

Figure 2 portrays the UV-visible spectra of the synthesized AgNPs using six plant extracts. The SPR bands at 440, 448, $435,445,425$ and $426 \mathrm{~nm}$ correspond to nanosilver synthesized using aqueous extracts of AK, SK, PAK, PGK, PG, and KFL, respectively. The broad Surface Plasmon Resonance band at 420-440 nm confirms the uniform distribution of AgNPs. The synthesized AgNPs observed for 3 months showed no discolouration or agglomeration suggesting its excellent stability.

XRD analysis

Figure 3 portrays the XRD patterns of the synthesized AgNPs using the aqueous extracts of A. dubius, A. polygonoides, A. sessilis, P. oleracea, $P$. grandis, and $K$. foetidissima. The diffraction peaks at $2 \theta=38^{\circ}, 44^{\circ}, 64^{\circ}$ and $77^{\circ}$ noted for the biosynthesized AgNPs, respectively, correspond to the (111), (200), (220) and (311) planes of face-centered cubic lattice of nanosilver. The additional peaks may be that of the capping agents or secondary metabolites present in the AgNPs solutions. The XRD data confirm the crystalline nature of the synthesized AgNPs formed using the plant extracts.

\section{SEM analysis}

Figure 4 clearly reveals the morphology of the nanosilver synthesized using different plant extracts. Spherical-shaped AgNPs of size in the range 30-90 nm with uniform size distribution were noted in the A. dubius, A. polygonoides, A. sessilis, $P$. oleracea, and $K$. foetidissima embedded nanosilver. The biosynthesized AgNPs were found to be evenly distributed without agglomeration.

\section{TEM analysis}

TEM images of the synthesized AgNPs were recorded to ascertain its shape and size. These images further confirmed the formation of spherical AgNPs of uniform distribution without agglomeration (Fig. 5). The particle sizes of the synthesized AgNPs were found to be 5-25 nm for AKG, SKG, PAKG, PGKG, PGG, and KFG. Nanoparticles of size less than $100 \mathrm{~nm}$ are anticipated to have high surface area and good antimicrobial activity. The TEM images reveal the prospective antimicrobial nature of the synthesized AgNPs. 

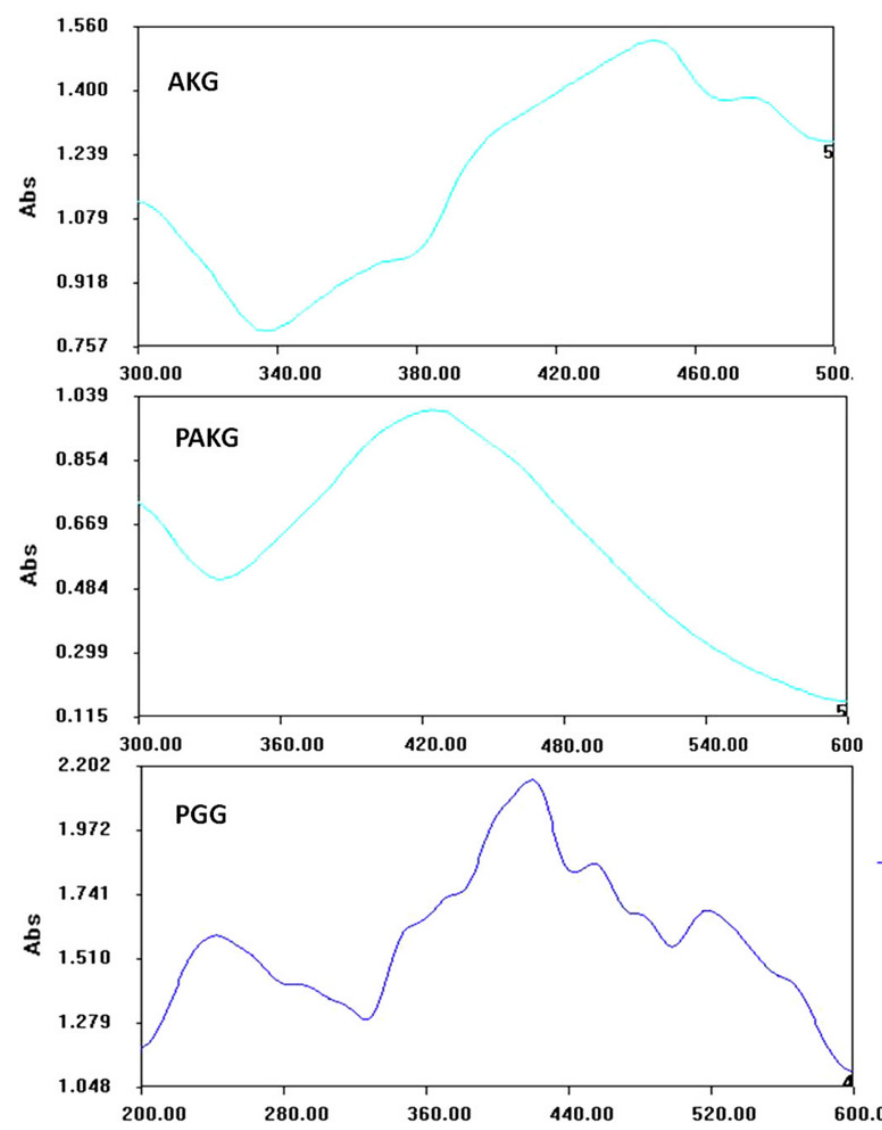
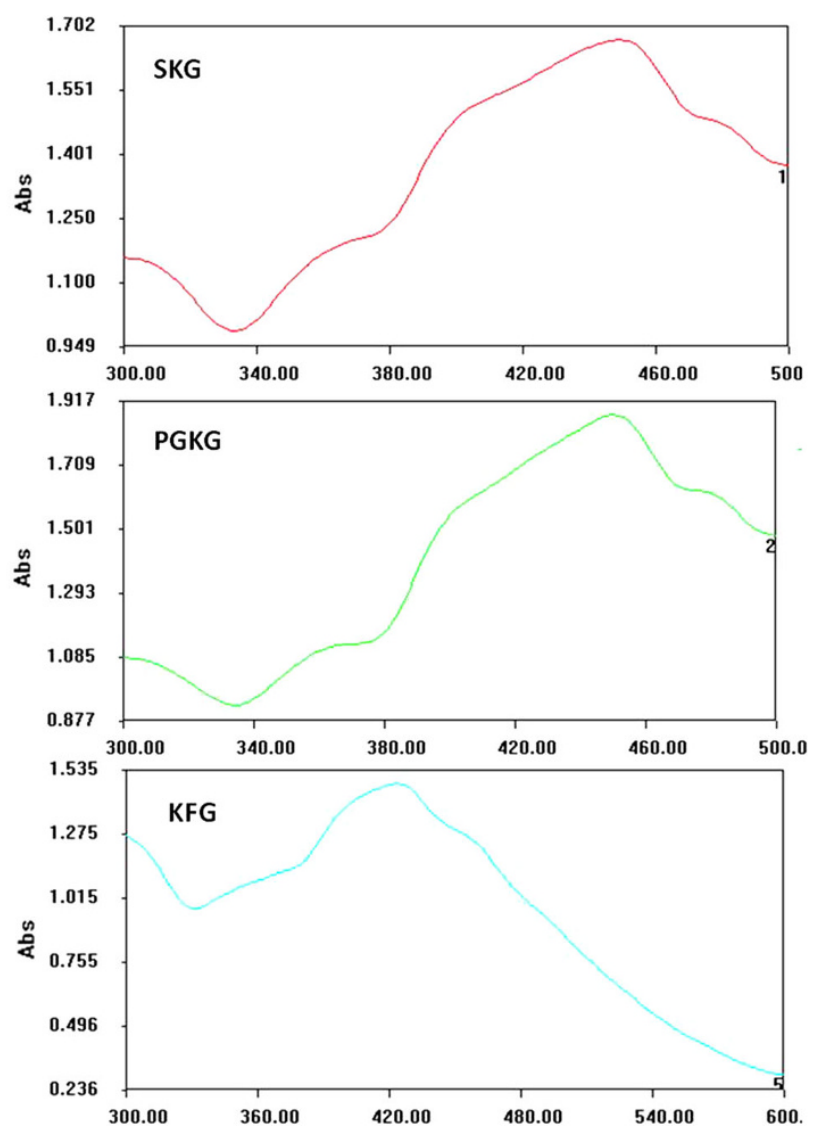

Fig. 2 UV-visible spectra of silver nanoparticles synthesized using the aqueous extracts of AK, SK, PAK, PGK, PG, and KF

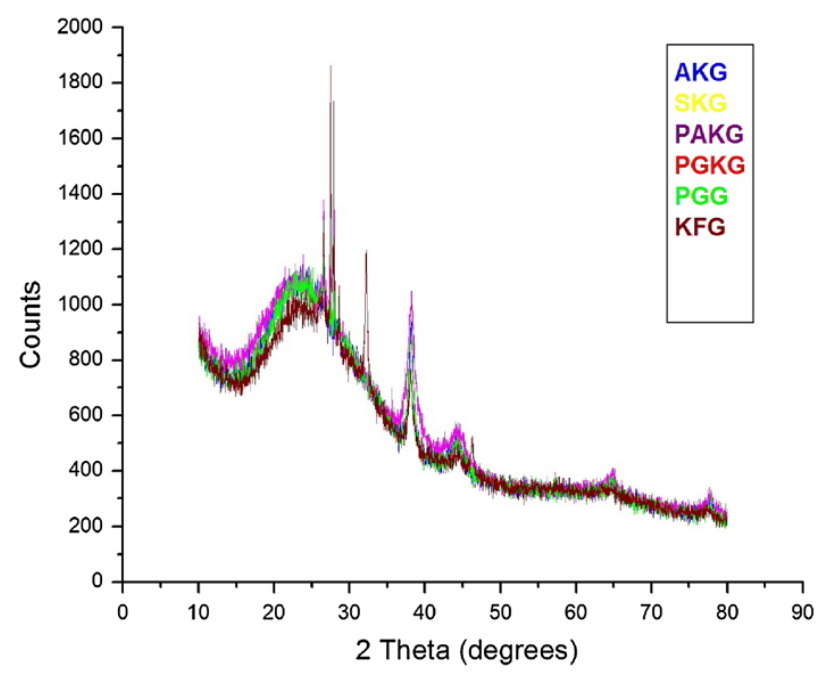

Fig. 3 XRD patterns of silver nanoparticles synthesized using the aqueous extracts of AK, SK, PAK, PGK, PG, and KF

Antifungal screening of synthesized silver nanoparticles

The MIC results portray fungicidal potential of AgNPs at very low concentrations (Figs. 6, 7). The inhibition of the fungal strains was greater than $50 \%$ compared to standard Fluconazole (Figs. 6, 7). The fungicidal activity depends on the yeast species and strains tested. Table 1 reveals the fungicidal activity to increase up to $600 \mu \mathrm{g}$ concentrations of AgNPs and remains constant with increased dosage of AgNPs. This supports the standardization of concentration of the synthesized AgNPs (AKG, SKG, PAKG, PGKG, PGG, and KFG) in antifungal study.

The results of the antifungal activity of the synthesized AgNPs $(20 \mu \mathrm{l})$ against $C$. albicans and $S$. cerevisiae showed good zones of inhibition compared to the standard Fluconazole (Fig. 8). Portulaca oleracea-mediated AgNP synthesis possessed high zone of inhibition viz. $12 \mathrm{~mm}$ and $18 \mathrm{~mm}$ against $C$. albicans and $S$. cerevisiae, respectively (Table 2). A. dubius, A. polygonoides, A. sessilis, and K. foetidissima aqueous extract-mediated AgNPs showed zones of inhibition similar to that of the standard.

The reduction in growth $C$. albicans was observed when concentration of polyvinylpyrrolidone (PVP)-stabilized silver nanoparticles (SNPs) was increased and the MIC value was found to be $70 \mathrm{ng} / \mathrm{ml}$. This effect was similar to the MIC values of standard antifungal drugs (amphotericin$0.5 \mu \mathrm{g} / \mathrm{ml}$, fluconazole- $8 \mu \mathrm{g} / \mathrm{ml}$ and ketoconazole- $8 \mu \mathrm{g} / \mathrm{ml}$ ) [19]. Saccharides-AgNPs and sodium chloride-AgNPs 


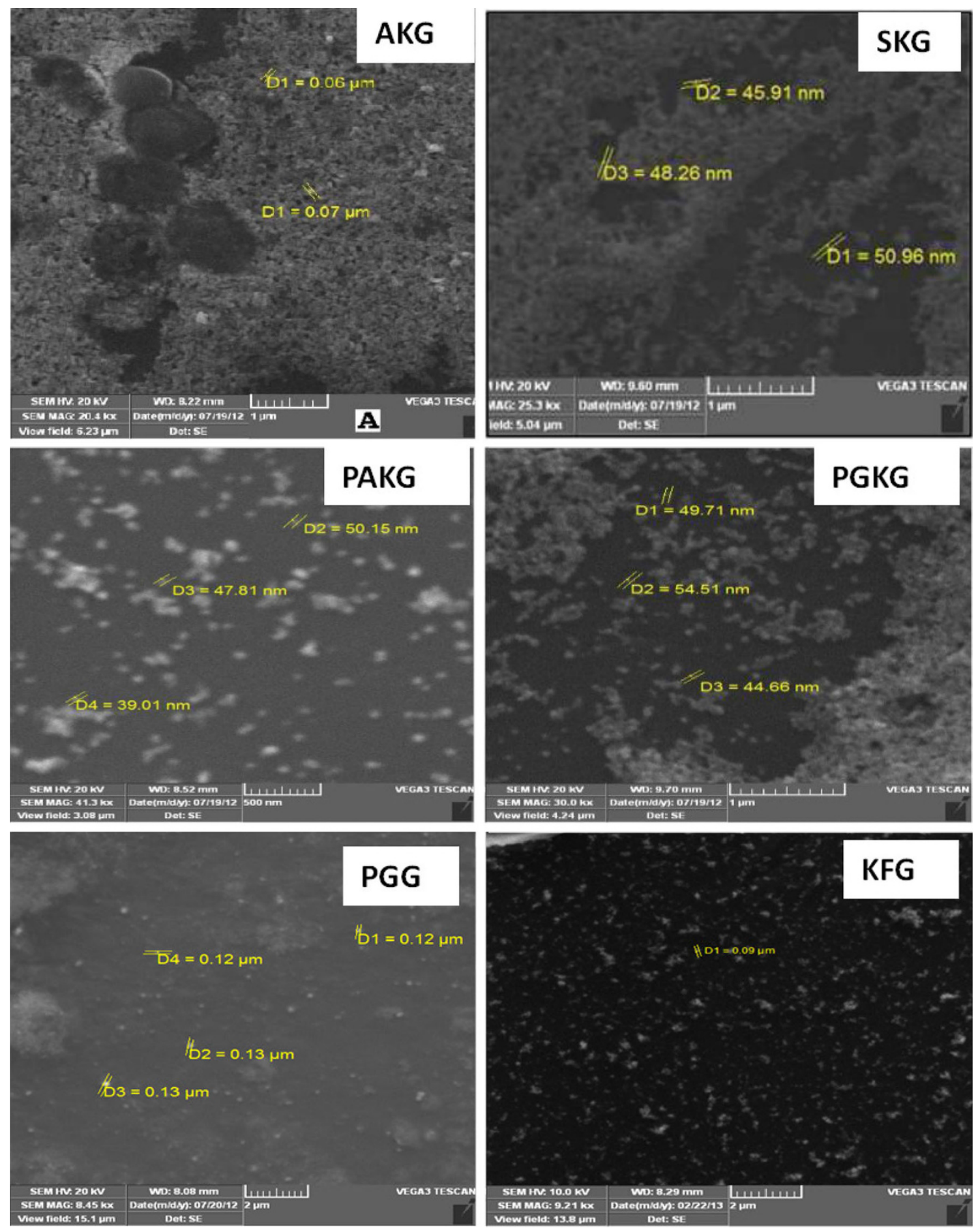

Fig. 4 SEM micrographs of silver nanoparticles synthesized using the aqueous extracts of AK, SK, PAK, PGK, PG, and KF

exhibited MIC value of $0.052 \mathrm{mg} / \mathrm{ml}$ to $0.1 \mathrm{mg} / \mathrm{ml}$ and $2-4 \mathrm{mg} / \mathrm{ml}$ against $C$. albicans, respectively [20]. Vertelov et al. (2008) reported the Myramistin-stabilized silver nanoparticles to be active at MIC value of $5 \mathrm{mg} / \mathrm{L}$ against $S$. cerevisiae [21]. Sulaiman et al. (2013) reported $E$. chapmaniana-assisted nanosilver to possess good zone of inhibition $(25 \mathrm{~mm})$ at a concentration of $0.02 \mathrm{mmol} / \mathrm{mL}$
[22]. Silver nanoparticles $(50 \mu \mathrm{g} / \mathrm{ml})$ synthesized using banana stem [23] showed no significant antimicrobial activity against $C$. albicans. Panacek et al. (2009) observed the MIC of AgNPs to be $0.21 \mathrm{mg} / \mathrm{L}$ (C. albicans) and $1.69 \mathrm{mg} / \mathrm{L}$ (C. parapsilosis) depicting appreciable antimicrobial activity [24]. The AgNPs synthesized using extracts of different parts of the same plant showed completely 


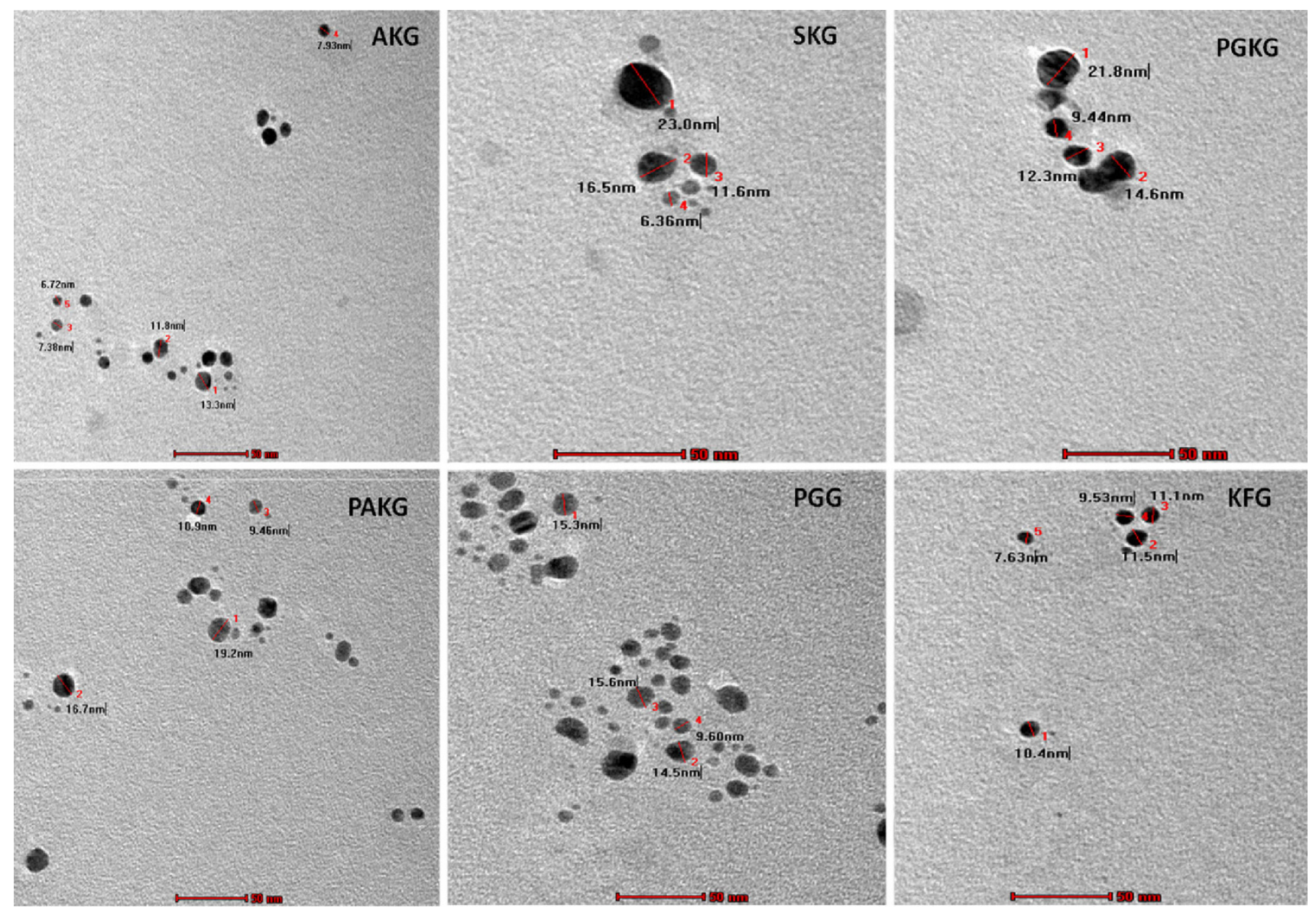

Fig. 5 TEM micrographs of silver nanoparticles synthesized using the aqueous extracts of AK, SK, PAK, PGK, PG, and KF

different antimicrobial effects [25]. The accomplishment of the aim of the present work is obvious when comparing the results of the antifungal activity of previous workers.

Analysis of the Apoptosis mechanism of synthesized AgNPs

The removal of damaged, mutated, unwanted or simply dispensable cells without an inflammatory reaction occurs due to the cellular suicide program termed apoptosis. This is a universally accepted cell elimination process in unicellular and multicellular organisms. The reactive oxygen species such as $\mathrm{O}_{2}, \mathrm{H}_{2} \mathrm{O}_{2}$ and $-\mathrm{OH}$ are the vital regulators which played a key role in apoptosis. The apoptosis in $C$. albicans by silver nanoparticles takes place through phosphatidylserine exposure and DNA damage followed by the activation of metacaspases. The mitochondrial integrity get disrupts thereby inducing the release of Cytochrome-C and programmed cell death occurs through ROS accumulation particularly hydroxyl free radical [26-28].

The unreacted silver ions in the silver nanoparticles or oxidized nanosilver play a main role in causing cell death against $S$. cerevisiae cells. The antifungal activity is unrelated to cell membrane. At 120 min time of exposure, AgNPs cause mechanical damage to membrane-bound transport proteins. During the later stages of exposure to nanosilver, the release of silver ions takes place. Hence, the antifungal activity of the synthesized silver nanoparticles mainly depends on the reducing agent, synthesis method, capping agent, nature of fungus, cell membrane and also size of nanosilver [29-33].

Silver nanoparticles induce apoptosis mainly through generation of hydroxyl radical. Biogenic synthesis of AgNPs using the extracts of A. dubius, A. polygonoides, A. sessilis, P. oleracea, and K. foetidissima may induce apoptosis due to the generation of reactive oxygen species (hydroxyl radicals) as well the reduction in production of hydroxyl radicals by the capping agents surrounding the synthesized AgNPs. The plants opted for study are rich in antioxidant sources and secondary metabolites which serve as excellent capping agents. Nanosilver synthesized chemically or the chemical molecules capped on the AgNPs might have the toxicity effect which sometimes causes death to the normal cells. With plant-mediated synthesis of AgNPs, there is no toxic effect as in conventionally synthesized AgNPs. Normal yeast and threat 


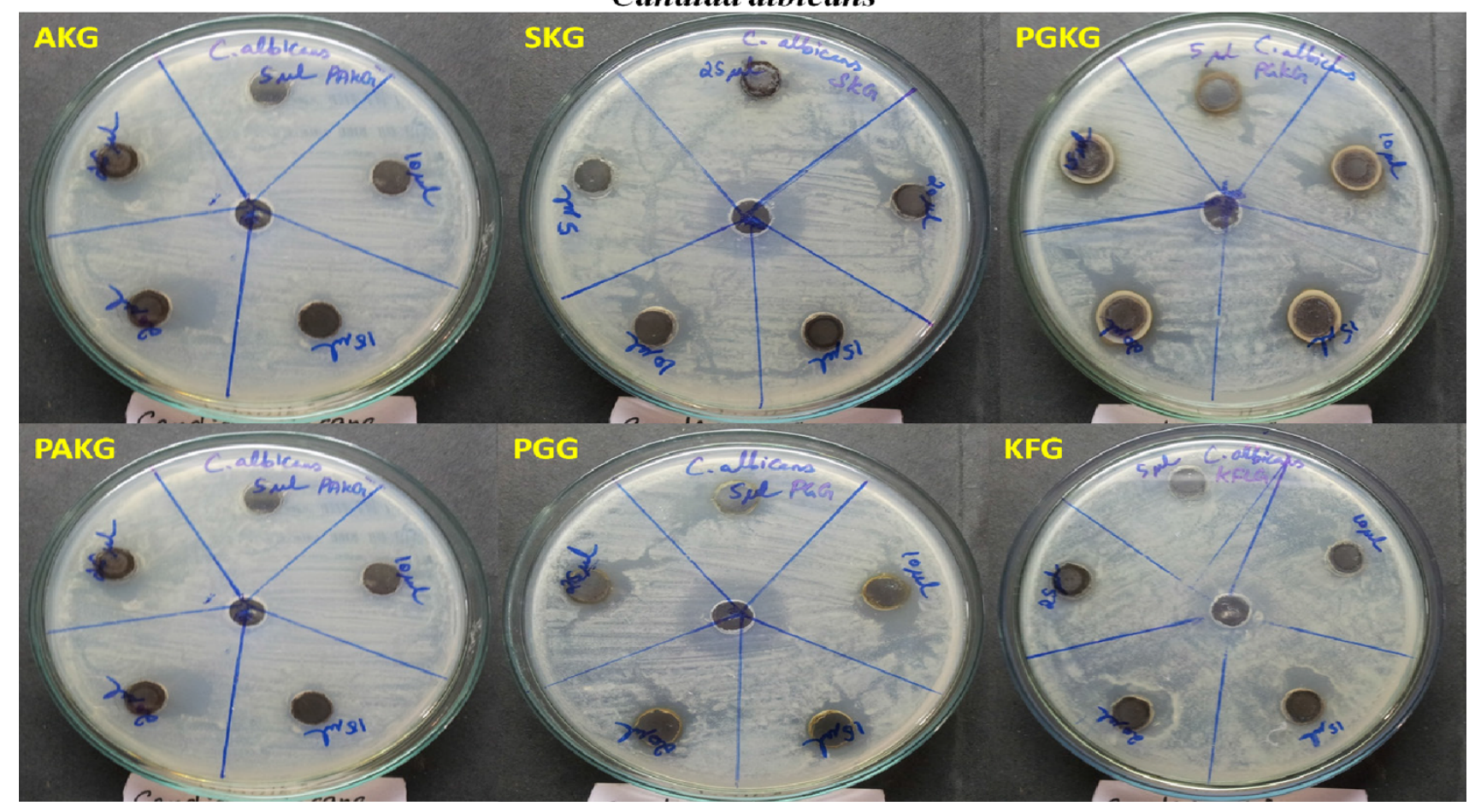

Fig. 6 MIC of antifungal activity of AKG, SKG, PAKG, PGKG, PGG, and KFG embedded silver nanoparticles against C. albicans

\section{Saccharomyces cerevisiae}

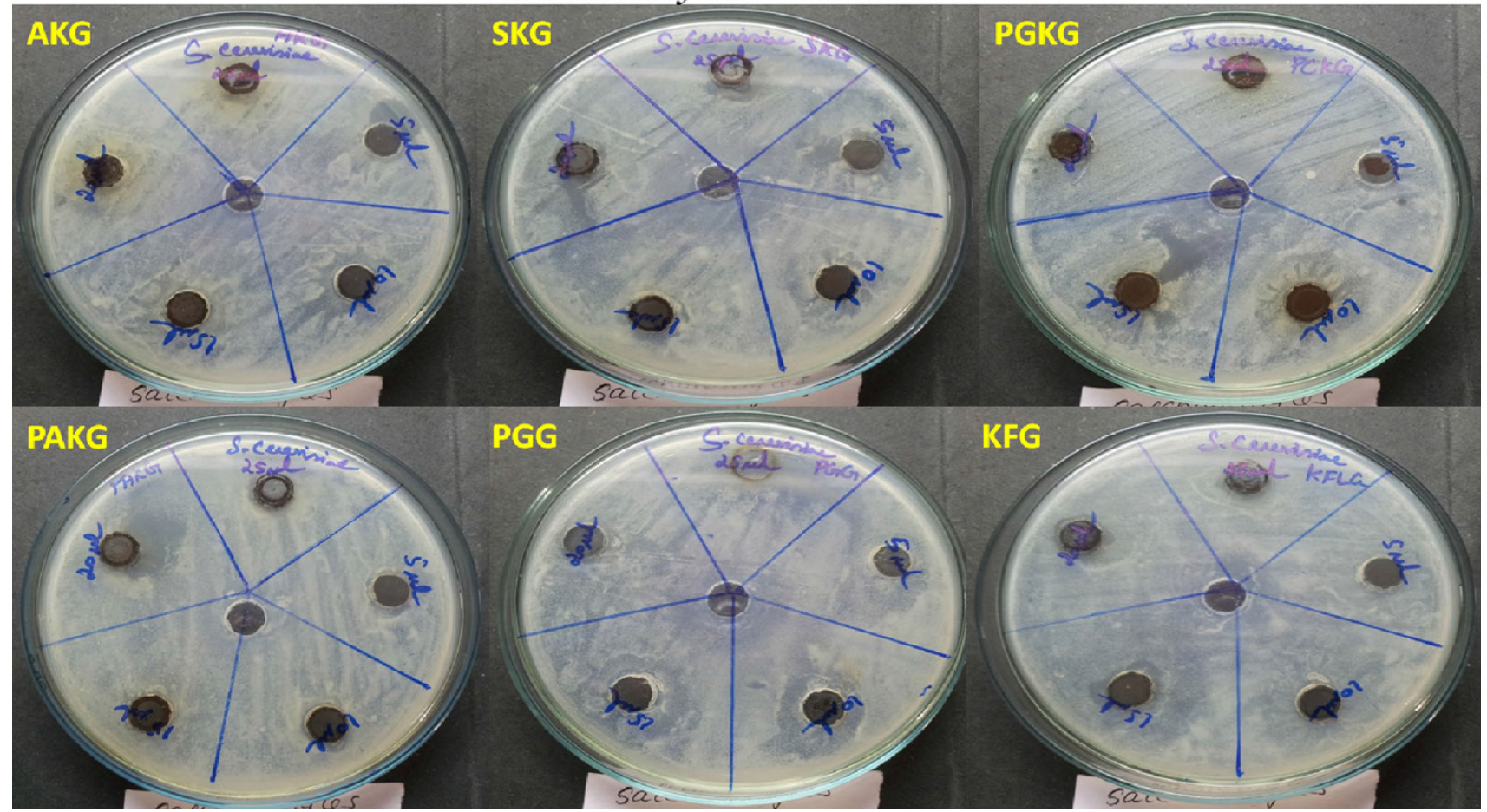

Fig. 7 MIC of antifungal activity of AKG, SKG, PAKG, PGKG, PGG, and KFG embedded silver nanoparticles against S. cerevisiae

causing fungus $C$. albicans screened for the antifungal activity with synthesized AgNPs revealed antifungal potential endorsing the interaction between the metal and microbes. This implants thrust for new antibiotics to the multiresistant microbes in future. Hence, the synthesized biogenic AgNPs may serve as a potential antifungal drug 
Table 1 MIC studies-zone of inhibition of synthesized silver nanoparticles against $C$. albicans and $S$. cerevisiae

\begin{tabular}{|c|c|c|c|c|c|c|c|c|c|c|c|}
\hline \multirow[t]{2}{*}{ S. No } & \multirow[t]{2}{*}{ Samples } & \multicolumn{5}{|c|}{ Candida albicans $(\mu \mathrm{g})$} & \multicolumn{5}{|c|}{ Saccharomyces cerevisiae $(\mu \mathrm{g})$} \\
\hline & & 200 & 400 & 600 & 800 & 1,000 & 200 & 400 & 600 & 800 & 1,000 \\
\hline 1. & AKG & 7 & 7 & 8 & 8 & 9 & 8 & 9 & 9 & 10 & 9 \\
\hline 2. & SKG & 7 & 8 & 9 & 10 & 10 & 9 & 9 & 10 & 10 & 9 \\
\hline 3. & PGKG & 10 & 11 & 12 & 11 & 10 & 8 & 9 & 9 & 10 & 9 \\
\hline 4. & PAKG & 9 & 10 & 12 & 11 & 12 & 11 & 14 & 19 & 12 & 12 \\
\hline 5. & PGG & 7 & 7 & 8 & 9 & 7 & 7 & 8 & 8 & 9 & 8 \\
\hline 6. & KFLG & 6 & 7 & 8 & 8 & 7 & 11 & 12 & 14 & 14 & 12 \\
\hline
\end{tabular}

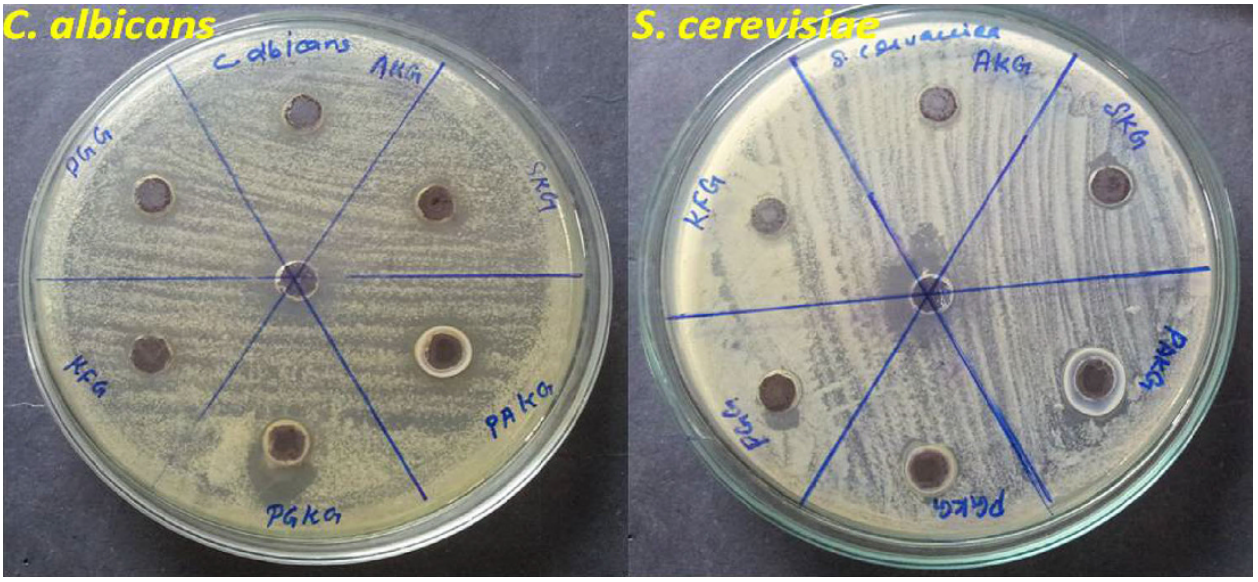

Fig. 8 Antifungal activity of AKG, SKG, PAKG, PGKG, PGG, and KFG embedded silver nanoparticles against $C$. albicans and $S$. cerevisiae
Table 2 Zone of inhibition of positive control and synthesized silver nanoparticles against $C$. albicans and $S$. cerevisiae

\begin{tabular}{lllc}
\hline S. No & Samples & \multicolumn{2}{c}{ Zone of inhibition $(\mathrm{mm})$} \\
\cline { 3 - 4 } & & C. albicans & S. cerevisiae \\
\hline 1. & STD (Fluconazole) & 12 & 10 \\
2. & AKG & 8 & 9 \\
3. & SKG & 9 & 10 \\
4. & PAKG & $\mathbf{1 2}$ & $\mathbf{1 9}$ \\
5. & PGKG & 12 & 8 \\
6. & PGG & 8 & 8 \\
7. & KFG & 8 & 14 \\
\hline
\end{tabular}

Bold values indicate the highest zone of inhibition

and can find applications in medical and pharmaceutical fields.

\section{Conclusion}

Silver nanoparticles of particle size less than $25 \mathrm{~nm}$ were synthesized using the aqueous extracts of A. dubius, A. polygonoides, A. sessilis, $P$. oleracea, $P$. grandis, and $K$. foetidissima by sonication method. The TEM images revealed the size of synthesized AgNPs to be 5-25 nm without agglomeration. The antifungal activity of the synthesized AgNPs against $S$. cerevisiae was significant. Apoptosis of fungi by biogenic AgNPs may be because of the generation of reactive oxygen species and decreased production of hydroxyl radicals due to the phytoconstituents capping the synthesized AgNPs. Thus, the plant-mediated AgNPs hopefully may promote development of new drugs for future generation against the multiresistant pathogens.

Acknowledgments The authors thank the Avinashilingam Institute for Home Science and Higher Education for Women University, Coimbatore, Tamil Nadu, for providing research facilities, Department of Physics, Avinashilingam University, for recording XRD, Periyar Maniammai University for recording SEM and Department of Nanoscience and Nanotechnology, Tamil Nadu Agricultural University, Coimbatore, for recording TEM. We thank KMCH College of Pharmacy for their help in antifungal studies.

Open Access This article is distributed under the terms of the Creative Commons Attribution License which permits any use, distribution, and reproduction in any medium, provided the original author(s) and the source are credited.

\section{References}

1. John, T.J., Dandona, L., Sharma, V.P., Kakkar, M.: Continuing challenge of infectious diseases in India. Lancet 377, 252-269 (2011) 
2. Kent, M. M., Yin, S.: Controlling infectious diseases. Popul. Bull. 61, No. 2 (Washington: Population Reference Bureau, 2006). Available from: http://www.prb.org/pdf06/61.2infectiousdiseases. pdf

3. Molero, G., Díez-Orejas, R., Navarro-García, F., Monteoliva, L., Pla, J., Gil, C., Sánchez-Pérez, M., Nombela, C.: Candida albicans: genetics, dimorphism and pathogenicity. Intern. Microbiol. 1(2):95-106 (1998); PMID 10943347

4. Berman, J., Sudbery, P.E.: Candida albicans: A molecular revolution built on lessons from budding yeast. Nat. Rev. Genet. 3, 919-930 (2002)

5. Nasution, A.I.: Virulence factor and pathogenicity of Candida albicans in oral candidiasis. World J Dent. 4(4), 267-271 (2013)

6. Meran, Z. D.: The use of silver nanoparticles as an antifungal coating on silicone facial prosthesis. Dissertation, University of Plymouth, 2013. Available from: http://pearl.plymouth.ac.uk/bit stream/.../2013Meran10381005ResM.pdf..pdf

7. Karathia, H., Vilaprinyo, E., Sorribas, A., Alves, R.: Saccharomyces cerevisiae as a model organism: A Comparative study. PLoS One 6(2), e16015 (2011). doi:10.1371/journal.pone. 0016015

8. Hohmann, S., Krantz, M., Nordlander, B.: Yeast osmoregulation. Methods Enzymol. 428, 29-45 (2007)

9. Nasheuer, H.P., Smith, R., Bauerschmidt, C., Grosse, F., Weisshart, K.: Initiation of eukaryotic DNA replication: regulation and mechanisms. Prog. Nucleic Acid Res. Mol. Biol. 72, 41-94 (2002)

10. Brocard-Masson, C., Dumas, B.: The fascinating world of steroids: $S$. cerevisiae as a model organism for the study of hydrocortisone biosynthesis. Biotechnol. Genet. Eng. Rev. 22, 213-252 (2006)

11. Jain, P.K., Huang, X., El-Sayed, I.H., El-Sayed, M.A.: Noble metals on the nanoscale: optical and photothermal properties and some applications in imaging, sensing, biology and medicine. Acc. Chem. Res. 41, 1578-1586 (2008)

12. Sharma, V.K., Yngard, R.A., Lin, Y.: Silver nanoparticles: green synthesis and their antimicrobial activities. Adv. Colloid Interfac. Sci. 145, 83-96 (2009)

13. Roopan, S.M., Rohita, Madhumitha, G., Rahuman, A. A., Kamaraj, C., Bharathi, A., Surendra, T. V.: Low-cost and ecofriendly phyto-synthesis of silver nanoparticles using Cocos nucifera coir extract and its larvicidal activity. Ind. Crop. Prod., 43:631-635 (2013)

14. Ravi, S.S., Christena, L.R., SaiSubramanian, N., Anthony, S.P.: Green synthesized silver nanoparticles for selective colorimetric sensing of $\mathrm{Hg}^{2+}$ in aqueous solution at wide $\mathrm{pH}$ range. Analyst 138(15), 4370-4377 (2013)

15. Prabhu, S., Poulose, E.K.: Silver nanoparticles: mechanism of antimicrobial action, synthesis, medical applications, and toxicity effects. Int. Nano. Lett. 2, 32 (2012)

16. Saklani, V., Suman Jain, V. K.: Microbial synthesis of silver nanoparticles: a review. J. Biotechnol. Biomaterial. S13:007 (2012). doi:10.4172/2155- 952X.S13-007. Available from: http:// dx.doi.org/10.4172/2155-952X.S13-007

17. Nadagouda, M.N., Iyanna, N., Lalley, J., Han, C., Dionysiou, D.D., Varma, R.S.: Synthesis of silver and gold nanoparticles using antioxidants from Blackberry, Blueberry, Pomegranate and Turmeric extracts. ACS Sustainable Chem. Eng. 2, 1717-1723 (2014)

18. Bonde, S.R., Rathod, D.P., Ingle, A.P., Ade, R.B., Gade, A.K., Rai, M.K.: Murraya koenigii-mediated synthesis of silver nanoparticles and its activity against three human pathogenic bacteria. Nanosci. Methods 1, 25-36 (2012)
19. Selvaraj, M., Pandurangan, P., Ramasami, N., Rajendran, S.B., Sangilimuthu, S.N., Perumal, P.: Highly potential antifungal activity of quantum-sized silver nanoparticles against Candida albicans. Appl. Biochem. Biotechnol. 173, 55-66 (2014)

20. Panacek, A., Kolar, M., Vecerova, R., Prucek, R., Soukupova, J., Krystof, V., Hamal, P., Zboril, R., Kvitek, L.: Antifungal activity of silver nanoparticles against Candida spp. Biomaterials 30, 6333-6340 (2009)

21. Vertelov, G., Krutyakov, Y., Efremenkova, O., Olenin, A., Lisichkin, G.: A versatile synthesis of highly bactericidal Myramistin- stabilized silver nanoparticles. Nanotechnology 19 (2008), doi:10.1088/0957-4484/19/35/355707

22. Sulaiman, G.M., Mohammed, W.H., Marzoog, T.R., Al-Amiery, A.A.A., Kadhum, A.A.A.H., Mohamad, A.B.: Green synthesis, antimicrobial and cytotoxic effects of silver nanoparticles using Eucalyptus chapmaniana leaves extract. Asian Pac. J. Trop. Biomed. 3(1), 58-63 (2013)

23. Das, J., Velusamy, P.: Biogenic synthesis of antifungal silver nanoparticles using aqueous stem extract of Banana. Nano. Biomed. Eng. 5(1):34-38 (2013). Available from: doi:10.5101/ nbe.v5i1.p34-38

24. Panacek, A., Kolar, M., Vecerova, R., Prucek, R., Soukupova, J., Krystof, V., Hamal, P., Zboril, R., Kvitek, L.: Antifungal activity of silver nanoparticles against Candida spp. Biomaterials 30, 6333-6340 (2009)

25. Vinod Kumar, V., Christena, L.R., SaiSubramanian, N., Anthony, S.P.: Bio-functionalized silver nanoparticles for selective colorimetric sensing of toxic metal ions and antimicrobial studies. Spectrochim. Acta Part A Mol. Biomol. Spectrosc. 129, 35-42 (2014)

26. Monteiro, D.R., Gorup, L.F., Silva, S., Negri, M., Camargo, E.R., Oliveira, R., Barbosa, D.B., Henriques, M.: Silver colloidal nanoparticles: antifungal effect against adhered cells and biofilms of Candida albicans and Candida glabrata. Biofouling 27(7), 711-719 (2011)

27. Kim, K.J., Sung, W.S., Moon, S.K., Choi, J.S., Kim, J.G., Lee, D.G.: Antifungal effect of silver nanoparticles on Dermatophytes. J. Microbiol. Biotechnol. 18(8), 1482-1484 (2008)

28. Kim, K.J., Sung, W.S., Suh, B.K., Moon, S.K., Choi, J.S., Kim, J.G., Lee, D.G.: Antifungal activity and mode of action of silver nano-particles on Candida albicans. Biometals 22, 235-242 (2009)

29. Rockenfeller, P., Madeo, F.: Apoptotic death of ageing yeast. Exp. Gerontol. 43, 876-881 (2008)

30. Oh, J.Y., Baek, Y.M., Kim, S.W., Hwang, H.J., Hwang, H.S., Lee, S.H., Yun, J.W.: Apoptosis of human hepatocarcinoma (HepG2) and neuroblastoma (SKN-SH) cells induced by polysaccharides-peptide complexes produced by submerged mycelial culture of an entomopathogenic fungus Cordyceps sphecocephala. J. Microbiol. Biotechnol. 18, 512-519 (2008)

31. Madeo, F., Frohlich, E., Ligr, M., Grey, M., Sigrist, S.J., Wolf, D.H., Frohlich, K.U.: Oxygen stress: A regulator of apoptosis in yeast. J. Cell Biol. 145, 57-767 (1999)

32. Kudrinskiy, A.A., Ivanov, A. Y., Kulakovskaya, E. V., Klimov, A. I., Zherebin, P. M., Khodarev, D. V., Anh-Tuan, L., Tam, L. T., Lisichkin, G. V., Krutyakov, Y. A.: The mode of action of silver and silver halides nanoparticles against Saccharomyces cerevisiae cells. J. Nanopar., Article ID 568635, p 7 (2014). Available from: http://dx.doi.org/10.1155/2014/568635

33. Niazi, J.H., Sang, B.I., Kim, Y.S., Gu, M.B.: Global gene response in Saccharomyces cerevisiae exposed to silver nanoparticles. Appl. Biochem. Biotechnol. 164, 1278-1291 (2011) 